\title{
1 Quantification of archaea-driven freshwater nitrification: from 2 single cell to ecosystem level
}

3

4

6

Franziska Klotz ${ }^{1}$, Katharina Kitzinger ${ }^{2}$, David Kamanda Ngugi ${ }^{3}$, Petra Büsing ${ }^{3}$, Sten Littmann ${ }^{2}$, Marcel M. M. Kuypers ${ }^{2}$, Bernhard Schink ${ }^{1}$, and Michael Pester ${ }^{1,3,4^{*}}$

1. Department of Biology, University of Konstanz, Universitätsstrasse 10, Konstanz, D-78457, Germany

2. Max Planck Institute for Marine Microbiology, Celsiusstrasse 1, D-28359 Bremen, Germany.

3. Leibniz Institute DSMZ - German Collection of Microorganisms and Cell Cultures, Inhoffenstr. 7B, D-38124 Braunschweig, Germany

4. Technical University of Braunschweig, Institute for Microbiology, Spielmannstrasse 7, D-38106 Braunschweig, Germany

Short title: Archaeal nitrification in lakes

Keywords: freshwater lake | hypolimnion | nitrification | growth rate | cell-specific rate | gene transcription | AOA | ammonia oxidation 
Archaeal nitrification in lakes

\section{Abstract}

Deep oligotrophic lakes sustain large archaeal populations of the class Nitrososphaeria in their hypolimnion. They are thought to be the key ammonia oxidizers in these freshwater systems and as such responsible for the rate-limiting step in nitrification. However, the impact that planktonic Nitrososphaeria have on $\mathrm{N}$ cycling in lakes is severely understudied and yet to be quantified. Here, we followed this archaeal population in one of Central Europe's largest lakes, Lake Constance, over two consecutive years using metagenomics and metatranscriptomics combined with stable isotopebased activity measurements. A single, highly abundant and transcriptionally active freshwater ecotype of Nitrososphaeria dominated the nitrifying community. Phylogenomic analysis of its metagenome-assembled genome showed that this ecotype represents a new lacustrine Nitrosopumilus species. Stable isotope probing revealed that Nitrososphaeria incorporated significantly more ${ }^{15} \mathrm{~N}$-labeled ammonium than most other microorganisms at near-natural conditions and oxidized ammonia at an average rate of $0.22 \pm 0.11 \mathrm{fmol} \mathrm{cell}^{-1} \mathrm{~d}^{-1}$. This translates to 1.9 gigagram of ammonia oxidized per year, corresponding to $12 \%$ of the $\mathrm{N}$-biomass produced annually by photosynthetic organisms in Lake Constance. Here, we show that ammonia-oxidizing archaea play an equally important role in the nitrogen cycle of deep oligotrophic lakes as their counterparts in marine ecosystems.

\section{Introduction}

Freshwater lakes are important drinking water reservoirs. To be suitable for drinking water and to prevent toxicity for fish, ammonia must not accumulate. Nitrification prevents an accumulation of ammonia and converts it to nitrate via nitrite, with ammonia oxidation being the rate-limiting step ${ }^{1}$. Although nitrification does not directly change the inventory of inorganic $\mathrm{N}$ in freshwater ecosystems, it represents a critical link between mineralization of organic $\mathrm{N}$ and its eventual loss as $\mathrm{N}_{2}$ to the atmosphere by denitrification or anaerobic ammonium oxidation ${ }^{1}$. The process of ammonia oxidation is catalyzed by three different microbial guilds. Two of these, the ammonia-oxidizing archaea $(A O A)^{2,3}$ and the ammonia-oxidizing bacteria $(A O B)^{4}$ oxidize ammonia to nitrite and depend on nitrite-oxidizing bacteria (NOB) ${ }^{5}$ to complete nitrification by further oxidation of nitrite to nitrate. The third guild oxidizes ammonia directly to nitrate and is therefore referred to as complete ammonia oxidizers (comammox) $)^{6,7}$.

In general, the ratio of $A O A$ to $A O B$ decreases with increasing trophic state of freshwater lakes, as $A O B$ have a preference for increased inorganic nitrogen loading and $A O A$ are sensitive towards copper complexation by organic matter ${ }^{8-14}$. In contrast, comammox bacteria were detected at very low abundances in lacustrine systems, if at all ${ }^{15,16}$. In snapshot analyses of oligotrophic lakes, AOA typically outnumbered $\mathrm{AOB}$, especially in the deep oxygenated hypolimnion, and constituted up to 
Archaeal nitrification in lakes

$19 \%$ of the archaeal and bacterial picoplankton ${ }^{10,15,17-20}$. These observations resemble the situation in marine ecosystems, where AOA account for up to $40 \%$ of all microorganisms in the deep sea and thus are estimated to be among the most numerous microorganisms on earth ${ }^{21,22}$. In contrast to marine ecosystems, the impact that planktonic freshwater AOA have on $\mathrm{N}$ cycling in oligotrophic lakes, which are often important drinking water reservoirs, is severely understudied and yet to be quantified.

Lake Constance is an oligotrophic, fully oxygenated lake that provides drinking water to more than five million people ${ }^{23}$. Being the second largest lake by volume in Central Europe, it represents an important model habitat for limnological processes ${ }^{24}$. A year-round survey of Lake Constance waters established that a single 16S rRNA gene-ecotype of AOA, related to the genus Nitrosopumilus (class Nitrososphaeria, formerly known also as Thaumarchaeota ${ }^{25}$ ), constituted the largest nitrifier population along the depth profile throughout the year, with $A O B$ being two orders of magnitude less abundant ${ }^{16}$. At the same time, comammox bacteria were below the detection limit as based on diagnostic PCR of the amoA gene ${ }^{16}$, which codes for the structural subunit of the key enzyme for ammonia oxidation, ammonia monooxygenase. Here, we link the large prevailing AOA population in this oligotrophic lake with nitrification activity and quantify this important ecosystem service at the single-cell, population, and ecosystem level.

\section{Results \& Discussion}

AOA account for $8-39 \%$ of total archaea and bacteria in the hypolimnion

Depth profiles of total ammonium $\left(\mathrm{NH}_{4}{ }^{+}+\mathrm{NH}_{3}\right)$ and nitrate showed typical inverse concentration profiles during periods of primary productivity (Fig. 1a-c). Total ammonium decreased and nitrate increased towards the hypolimnion, indicative of active ammonium consumption and nitrate production in hypolimnetic waters, presumably by nitrification (Fig. 1b,c). Hence, we decided to follow annual dynamics of the AOA population in the central part of the hypolimnion at $85 \mathrm{~m}$ depth. Copy numbers of Lake Constance-specific archaeal amoA genes were enumerated by quantitative $\mathrm{PCR}$ (qPCR). As amoA is typically present as a single copy gene in $\mathrm{AOA}^{26}$, amoA copy numbers were compared to total archaeal and bacterial 16S rRNA gene copy numbers to estimate AOA relative abundance. This confirmed the presence of a large prevailing AOA population in the hypolimnion ranging from $8.0 \pm 0.9 \%$ to $38.9 \pm 5.7 \%$ of the archaeal and bacterial picoplankton. Absolute

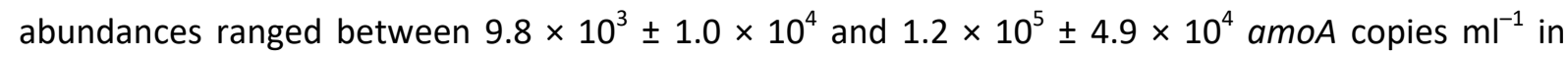
winter and summer, respectively, with a mean copy number of $4.3 \times 10^{4} \mathrm{amoA}$ copies $\mathrm{ml}^{-1}$ (Fig. $1 \mathrm{~d}$ ). These GPCR results corresponded well to direct Nitrososphaeria cell counts based on catalyzed reporter deposition fluorescence in situ hybridization (CARD-FISH) at two selected time points 
(Supplementary Fig. 1). We therefore use the terms AOA and Nitrososphaeria as synonyms from here on.

\section{A freshwater-specific $A O A$ species dominates the nitrifier community}

To gain insight into the genetic repertoire of the AOA, we conducted a metagenomic survey of hypolimnetic waters covering nine time points from Nov 2017 to Dec 2018 (Fig. 1d). Best assembly results were obtained by a co-assembly of the winter datasets Nov 2017, Dec 2017 and Feb 2018, which resulted in a single metagenome-assembled genome (MAG) related to Nitrososphaeria that was further refined by long PacBio reads for scaffolding. This resulted in a high quality assembly of

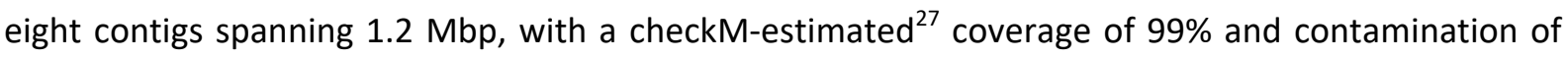
$0 \%$ (Supplementary Table 1). The 16S rRNA gene of MAG AOA-LC4 was $100 \%$ identical to the single $16 \mathrm{~S}$ rRNA gene-ecotype that was previously shown in an amplicon-based study to outnumber all other $A O A$ and $A O B$ populations by at least two orders of magnitude throughout the depth profile of Lake Constance ${ }^{16}$ and thus represents the main ammonia oxidizer of this lake. An index of replication $\left(\right.$ iREP) ${ }^{28}$ analysis indicated active replication of the AOA-LC4 population throughout the entire year with average values of $50 \pm 19 \%$ and ranging from a minimum of 34\% in November/December 2017 to a maximum of $90 \%$ in October 2018 (Supplementary Table 1). Although the iRep algorithm was recently questioned to work with population genomes integrating over many co-occurring but heterogeneous close relatives ${ }^{29}$, it performs well for uniform population genomes such as pure cultures $^{28,30,31}$. We consider the extremely low and highly skewed AOA diversity in Lake Constance ${ }^{16}$ to be rather representative of the latter case. Phylogenomic analysis placed AOA-LC4 within a freshwater/brackish water-associated clade of the Nitrosopumilaceae, which was distinct from marine representatives (Supplementary Fig. 2). Closest relatives were MAGs retrieved from Lake Baikal (G182) and from the Caspian Sea (Casp-thauma1), which, together with AOA-LC4, represent a new species within the genus Nitrosopumilus based on genome-wide average nucleotide and amino acid identities (Supplementary Fig. 3). Therefore, AOA-LC4 is a representative of AOA in major inland water bodies.

AOA-LC4 encoded the core genetic repertoire of Nitrosopumilus species ${ }^{32,33}$. This included all genes necessary for oxidation of ammonia to hydroxylamine in the canonical arrangement $\operatorname{amo} B C x A$, as well as genes with a proposed function in further oxidation of hydroxylamine to nitrite, i.e. genes encoding (putative) multicopper oxidases including a postulated reversely operating nitrite reductase $(\text { ("nirK") })^{34,35}$. In addition, AOA-LC4 carries genes for a urea transporter (dur3), urea amidohydrolase (ure $A B C$ ), and urease accessory proteins (ureDEFGH). Furthermore, it is prototrophic for the vitamins Thiamine (B1), Riboflavin (B2), Biotin (B7) and Cobalamin (B12). For carbon fixation, it encodes the 
energy-efficient variant of the 3-hydroxypropionyl/4-hydroxybutyryl pathway (Supplementary Fig. 4, Supplementary Table 2).

To obtain a complete picture of the nitrifying community, we screened all obtained MAGs and single contigs for the presence of $a m o A$ as indicator for all ammonia oxidizers, $n x r B$ (encoding the beta subunit of nitrite oxidoreductase) as indicator for all nitrite-oxidizing bacteria ${ }^{36}$, or both genes in the same MAG/contig as indicator for comammox bacteria ${ }^{5}$. MAG AOB-LC263 encoded the bacterial $a m o A B$ genes and was affiliated with a novel genus within the Nitrosomonadaceae (Proteobacteria) (Supplementary Text and Supplementary Fig. 5, 6). In addition, we found two contigs (AOB-LC199628 and AOB-LC368213), which encoded either $a m o A B$ or amoCAB and were again related to the Nitrosomonadaceae (Supplementary Fig. 7). However, both contigs did not group into any of the binned MAGs that fulfilled our completeness criteria (>50\%). Two MAGs, NOB-LC32 and NOB-LC29, encoded $n \times r A B$ and $n \times r B$, respectively, and were related to Nitrospira lineage II (Nitrospirae) (Supplementary Text and Supplementary Fig. 8-10). Interestingly, we recovered a third Nitrospira lineage II MAG, COM-LC224 (Supplementary Fig. 8), which encoded both amoA and $n x r B$ (Supplementary Fig. 10, 11). Closer inspection identified the full set of amoCAB, hao, and $n \times r A B$ encoding the ammonia monooxygenase, hydroxylamine reductase, and nitrite oxidoreductase, respectively. This finding was further supported by the affiliation of MAG COM-LC224 to comammox clade $B$ as inferred by independent phylogenetic analysis of its concatenated single copy marker genes as well as its functional marker genes amoA and $n x r B$ (Supplementary Text and Supplementary Fig. $8,10,11)$. Throughout the year, MAGs AOB-LC263 and COM-LC224 as well as the contigs AOBLC199628 and AOB-LC368213 were 1-2 orders of magnitude less abundant than AOA-LC4 as inferred from mapping coverage results in the nine metagenomes (Supplementary Table 1). Similarly, MAGs NOB-LC32 and NOB-LC29 were one order of magnitude less abundant (Supplementary Table 1). This is consistent with results obtained three years earlier by $16 \mathrm{~S}$ rRNA gene amplicon sequencing and amoA screening ${ }^{16}$.

\section{AOA-LC4 is transcriptionally active throughout the year}

The dominance of AOA-LC4 was also reflected at the transcriptional level. In a metatranscriptome survey covering six time points from November 2018 to November 2019, amoA transcription of the AOA-LC4 population was consistently at least two orders of magnitude higher than of the individual AOB-LC263, AOB-LC199628, AOB-LC368213 or COM-LC224 populations (Fig. 2). Compared to $n x r B$ transcription of the NOB-LC32 and NOB-LC29 populations, amoA transcription of AOA-LC4 was consistently one order of magnitude higher, which reflects the relative abundance estimates based on normalized metagenomic coverage (Supplementary Table 1) and 16S rRNA gene amplicons ${ }^{16}$. Interestingly, the transcription of the COM-LC224 amoA gene was one order of magnitude lower 


\section{Archaeal nitrification in lakes}

than of its $n \times r B$, suggesting the possible predominance of nitrite oxidation relative to complete ammonia oxidation to nitrate in this microorganism. Alternatively, the represented two enzymes have different turnover times or regulation mechanisms.

Detailed analysis of the seasonally resolved AOA-LC4 population transcriptome identified amoABC among the top ten transcribed genes at a steady level with little variation throughout the yearly cycle (Fig. 3, Supplementary Table 2). Transcription of amoABC was highly correlated $\left(r_{s} \geq 0.8\right)$ to each other and to transcription of "nirK" and a gene encoding a membrane-anchored PEFG-CTERM domain-containing multicopper oxidase (locus JW390_30004) (Supplementary Fig. 12). The latter two were previously postulated to be involved in the yet unresolved archaeal pathway of ammonia oxidation to nitrite ${ }^{33-35,37}$. On average, amoABC showed a 16 to 119 fold higher transcription than the highest transcribed genes encoding either proteins of the large $(r p / 12, r p / 21 e)$ or small ribosomal subunit (rps11, rps15), which we used as reference housekeeping genes (Fig. 3). Also amt and cdvB, encoding a high-affinity ammonium transporter and the putative cell division protein B2, respectively, were consistently found among the top ten highest transcribed genes. Since the active center of the archaeal ammonia monooxygenase is postulated to face the outside of the cytoplasmic membrane ${ }^{35}$, the high transcriptional levels of amt imply that ammonia was transported into the cell for ammonium assimilation, most likely for further biomass production as evidenced by the high transcriptional levels of $c d v B$. This is in line with the consistent transcription of genes encoding the 3-hydroxypropionate/4-hydroxybutyrate pathway for $\mathrm{CO}_{2}$ fixation, however, at 1 to 300 fold lower transcriptional levels as compared to the selected ribosomal reference genes (Fig. 3, Supplementary Table 2). Together, this resembles (meta-)transcriptomic data of actively growing AOA species in culture and in open marine waters with AOA-driven nitrification activity ${ }^{34}$. Therefore, we conclude that the AOA-LC4 population was actively oxidizing ammonia throughout the year. In contrast, genes associated with urea utilization were much less transcribed. While dur3 (encoding an urea transporter) was transcribed similar to the four highest transcribed ribosomal protein genes, ure $A B C$ (encoding urease) showed a 12 to 988 fold lower transcription. The same was true for ureDEFGH (encoding [putative] urease accessory proteins) with transcriptional levels either below the detection limit, or 43 to 1,507 fold lower. However, low transcription of urease and urease-associated genes has previously been shown to be a poor predictor for lack of urea-based nitrification of $\mathrm{AOA}^{34}$.

\section{AOA predominate ${ }^{15} \mathrm{~N}$-ammonium assimilation in the hypolimnion}

To link transcriptional with metabolic activity, we performed short-term (48 h) ${ }^{15} \mathrm{NH}_{4}{ }^{+}$-labeling experiments in parallel to our metatranscriptomic survey in November 2019. As described above, transcriptional activity of the AOA-LC4 population was high in these samples and exceeded other ammonia oxidizers' transcriptional levels (Fig. 2). As a measure of metabolic activity, incorporation of 
Archaeal nitrification in lakes

${ }^{15} \mathrm{~N}$-ammonium was analyzed at the single-cell level using nanoscale secondary ion mass spectrometry (nanoSIMS) coupled to CARD-FISH identification of AOA cells. All measured AOA cells $\left(n_{\text {cells }}=37\right)$ were metabolically active and incorporated ammonium at an average rate of $5.04 \pm 3.01$ amol $\mathrm{NH}_{4}^{+}$cell ${ }^{-1} \mathrm{~d}^{-1}$. The AOA population was significantly more enriched in ${ }^{15} \mathrm{~N}$ than the remaining picoplankton community ( $n_{\text {cells }}=105$, non-parametric Mann-Whitney U-test, $p<0.005$ ) (Fig. 4). Using the nanoSIMS results, we calculated single-cell $\mathrm{N}$-based growth rates of $0.012 \pm 0.006 \mathrm{~d}^{-1}$ for AOA at the in situ temperature of $4^{\circ} \mathrm{C}$. These rates are one order of magnitude lower than those previously observed in pure cultures of Nitrosopumilus maritimus ${ }^{3}$ or for AOA in marine subtropical waters ${ }^{38}$. This is explained by the higher incubation temperature of $28^{\circ} \mathrm{C}$ in the latter two studies. It should however be noted that two other studies in cold marine waters (ice-water to $\left.4^{\circ} \mathrm{C}\right)^{39,40}$ reported $\mathrm{AOA}$ growth rates comparable to growth rates of $N$. maritimus at $28^{\circ} \mathrm{C}^{3}$. The nanoSIMS data was further used to quantify AOA cell dimensions. The average AOA cell in Lake Constance is around $0.54 \pm 0.11 \mu \mathrm{m}$ in length and $0.39 \pm 0.10 \mu \mathrm{m}$ in width and has a volume of $0.048 \pm 0.035 \mu \mathrm{m}^{3}$. This translates into an average biomass of $46 \pm 15 \mathrm{fg}-\mathrm{C} \mathrm{cell}{ }^{-1}$ according to the volume-to-carbon relationship established recently by Khachikyan et al. ${ }^{41}$. When taking the total abundance of AOA into account (Fig. 1d), this sums up to $0.5-5.5 \mathrm{mg}-\mathrm{C} \mathrm{m}^{-3}$ (average $2.0 \mathrm{mg}-\mathrm{C} \mathrm{m}^{-3}$ ) stored in AOA cells in the hypolimnion. In comparison to phytoplankton biomass, which we inferred from depth-integrated Chlorophyll a measurements, and considering that the hypolimnion extends over $120 \mathrm{~m}$ at our sampling station, this AOA-stored carbon makes up $3.3-30.6 \%$ (average $12.3 \%$ ) of carbon stored in phytoplankton over the year's cycle (Fig. 1e).

\section{AOA oxidize 1.9 gigagram of ammonium per year in Lake Constance}

All independent lines of evidence obtained in this study arrive at the conclusion that the AOA-LC4 population is driving ammonia oxidation in Lake Constance, with a negligible contribution by $A O B$ and comammox bacteria. This natural setting posed the unique opportunity to quantify the ecosystem function exerted by planktonic AOA and to link this information to a single ecotype. We followed nitrification rates in the hypolimnion (85 $\mathrm{m}$ depth) by ${ }^{15} \mathrm{NH}_{4}{ }^{+}$incubations over four independent time points from June to November 2019. Nitrification rates were very similar within this time period with an average of $6.1 \pm 0.7 \mathrm{nmol} \mathrm{I}^{-1} \mathrm{~d}^{-1}$ (Table 1). Similar rates were observed in oligotrophic and deep Lake Superior, where total ammonium and nitrate contents were in the range found in Lake Constance ${ }^{19,42}$. Although the obtained rates are potential rates, the absence of an obvious activity lag phase and the linearity of the activities $\left(R^{2}=0.91-1.00\right)$ throughout the incubation time $(48 \mathrm{~h})$ point towards an active AOA-LC4 population in situ and a realistic rate determination (Supplementary Fig. 13). Our previously published estimate of the nitrification rate in Lake Constance was considerably higher but was based on ${ }^{15} \mathrm{~N}$-dilution from the nitrate pool ${ }^{16}$ instead of measuring direct conversion of ${ }^{15} \mathrm{~N}$-ammonium to ${ }^{15} \mathrm{~N}$-nitrite/nitrate (this study). In 
addition, the previous single time point estimate was based on a high variation of residual ${ }^{15} \mathrm{~N}$ in replicates. Therefore, we consider the replicated rate measurements presented in this study to be more realistic and conservative.

Measured bulk rates were normalized by archaeal amoA copy numbers for the June and November samples to determine cell-specific nitrification rates of the AOA population. At both time points, cellspecific rates were highly similar and averaged to $0.22 \pm 0.11 \mathrm{fmol} \mathrm{cell}^{-1} \mathrm{~d}^{-1}$ (Table 1 ). Like the calculated AOA growth rates, these cell-specific nitrification rates at $4^{\circ} \mathrm{C}$ are one order of magnitude lower than those observed for cultivated marine Nitrosopumilus species at 22 to $28^{\circ} \mathrm{C}^{3,43}$, or for $\mathrm{AOA}$ in marine subtropical waters ${ }^{44}$, as would be expected from the $Q_{10}$ temperature coefficient rule ${ }^{45}$. We used the obtained cell-specific rates to extrapolate AOA-driven nitrification over our complete data set of AOA abundances in Lake Constance (Fig. 1d). As a result, we estimate that about $48 \mathrm{mg} \mathrm{NH}_{4}{ }^{+} \mathrm{m}^{-3} \mathrm{y}^{-1}$ is oxidized by the AOA population. This translates to a total of 1.9 gigagram $\mathrm{NH}_{4}^{+}$ oxidized per year if integrated over the whole lake's hypolimnion $\left(38.1 \mathrm{~km}^{3}\right)$. In comparison, 15.7 gigagram of biomass- $\mathrm{N}$ are annually produced by primary production in the photic zone of Lake Constance, when considering the annual primary productivity rate of $220 \mathrm{~g} \mathrm{C} \mathrm{m}^{-2} \mathrm{y}^{-146}, 473 \mathrm{~km}^{2}$ surface area of Lake Constance ${ }^{24}$ and the Redfield ratio (C:N = 106:16). In conclusion, AOA-converted $\mathrm{N}$ corresponds to $12 \%$ of photosynthetic biomass- $\mathrm{N}$ produced in the photic zone of Lake Constance.

\section{Epilog proposal of "Candidatus Nitrosopumilus limneticus"}

Based on its phylogenetic placement, gANI values and habitat preference, we propose a new species name for AOA-LC4: “Candidatus Nitrosopumilus limneticus sp. nov." (lim.ne'ti.cus. N.L. masc. adj. limneticus (from Gr. limne, lake, swamp) belonging to a lake). "Candidatus Nitrosopumilus limneticus" encodes and transcribes genes essential for dissimilatory ammonia oxidation to nitrite and autotrophic $\mathrm{CO}_{2}$ fixation via the 3-hydroxypropionyl/4-hydroxybutyryl pathway. Its preferred habitat is the oxygenated hypolimnion of oligotrophic freshwater lakes.

\section{Conclusion}

Over the last two decades, reports accumulated that deep oligotrophic lakes sustain large populations of Nitrososphaeria in their hypolimnion ${ }^{15-20,47}$. Our study links these large archaeal populations to nitrification activity and quantifies this important ecosystem service at the single-cell, population, and ecosystem levels. We provide compelling evidence that AOA in a deep oligotrophic lake play an equally important role in the nitrogen cycle-both in terms of their relative abundance and nitrogen fluxes-as their counterparts in marine ecosystems $\mathrm{do}^{21,48}$. Lakes are considered sentinels of climate change responding to rising annual temperatures by changes in their physical, chemical and biological properties ${ }^{49}$. Lake Constance is not an exception; its surface waters have become increasingly much warmer, with an annual average increase of $0.9^{\circ} \mathrm{C}$ observed between 
Archaeal nitrification in lakes

1962 to $2014^{50}$. Further warming is predicted to continue at $0.03^{\circ} \mathrm{C} y^{-1}$ resulting in increasing thermal stratification and concomitant increased deoxygenation of deep hypolimnetic waters ${ }^{50}$. Here, we show that nitrification is a key process in the lake's nitrogen cycle, which we inferred to be driven by a single freshwater AOA ecotype, designated as Candidatus Nitrosopumilus limneticus. The results support the general view that the alpha diversity of $A O A$ is extremely low in freshwater lakes ${ }^{51-54}$. In turn, this raises the question how resilient this ecosystem service is to changes in the physical and chemical properties of freshwater lakes in the face of climate change. Answers to this question are interlinked with our quest for clean drinking water supply, since nitrification prevents the accumulation of harmful ammonium, and the quality of freshwater bodies for fisheries and other lacustrine fauna.

\section{Material and Methods}

\section{Study area and sampling procedure}

Lake Constance is a peri-alpine lake with a maximum depth of $251 \mathrm{~m}$, which is monomictic and turning over only in winter. Sampling was conducted the long-term ecological research station of the University of Konstanz $\left(47.75788^{\circ} \mathrm{N}, 9.12617^{\circ} \mathrm{E}\right)$, which is located in the northwestern branch of Upper Lake Constance with a maximum depth of around $140 \mathrm{~m}$ (Supplementary Fig. 14). Upper Lake Constance has a permanently oxygenated hypolimnion throughout the year. In this study, we refer to Lake Constance only including deep and oligotrophic Upper Lake Constance and excluding the smaller, shallow and mesotrophic Lower Lake Constance (Supplementary Fig. 14).

Vertical profiles of temperature and oxygen were measured down to the lake sediment with a multisampling probe (RBR Ltd.; Ottawa, Canada, Sea \& Sun Technology GmbH, Trappenkamp, Germany or bbe Moldaenke GmbH, Schwentinental, Germany). Nitrate and total ammonium $\left(\mathrm{NH}_{4}^{+}+\mathrm{NH}_{3}\right)$ concentrations were determined using the auto-analyzer and Seal analytics methods G-172-96 Rev. 12 and G-171-96 Rev. 14, respectively (SEAL Analytical GmbH, Norderstedt, Germany). For these measurements, $20 \mathrm{ml}$ water each from 13 depths between $1-135 \mathrm{~m}$ were taken, filtered through a Chromafil ${ }^{\circledR}$ GF/PET-20/25 filter (pore size 1.0 and $0.2 \mu \mathrm{m}$, VWR, Vienna, Austria) and stored at $-20^{\circ} \mathrm{C}$ until analysis. Samples obtained between July and November 2019 were measured by an alternative method: Nitrate was measured by ion chromatography (S150 Chromatography System, SYKAM) and total ammonium was measured fluorometrically by the ortho-phthaldialdehyde method ${ }^{55}$. Chlorophyll $a$ was sampled from 22 depths over a gradient of 0-60 m and analyzed spectrophotometrically after extraction in hot ethanol as described previously ${ }^{56}$, but without correcting for pheopigments.

For quantitative PCR and metagenome analyses, water was sampled from $85 \mathrm{~m}$ depth in three to four replicates (2.5-5.0 I). Water was pre-filtered through a $70 \mu \mathrm{m}$ and $30 \mu \mathrm{m}$ nylon mesh (Franz 


\section{Archaeal nitrification in lakes}

301

302

303

304

305

306

307

308

309

310

311

312

313

314

315

316

317

318

319

320

321

322

323

324

325

326

327

328

329

330

331

332

333

334

Eckert $\mathrm{GmbH}$, Germany) to remove larger organisms and was filtered on board first through $5 \mu \mathrm{m}$ and then through $0.2 \mu \mathrm{m}$ polycarbonate filters (47 mm, Merck, Darmstadt, Germany) using pressurized air. Filters were stored immediately on dry ice on board and at $-20^{\circ} \mathrm{C}$ in the laboratory until further processing. For metatranscriptome analyses, water was sampled in three replicates directly at the desired water depth of $85 \mathrm{~m}$ with a WTS-LV in-situ pump (McLane research laboratories, Inc., Massachusetts, USA). The pump was programmed to stop running after $1 \mathrm{~h}, 200$ I filtered water or if the flow rate reached a minimum of $500 \mathrm{ml} \mathrm{min}^{-1}$ (initial flow rate was set to 3,500 $\mathrm{ml} \mathrm{min}{ }^{-1}$ ). The amount of filtered water was recorded. Water was filtered serially through a $30 \mu \mathrm{m}$ mesh (Franz Eckert GmbH), $5 \mu \mathrm{m}$ and $0.22 \mu \mathrm{m}$ filters (142 mm, Merck). Filters with $5 \mu \mathrm{m}$ and $0.22 \mu \mathrm{m}$ pore size were stored immediately on dry ice on board and at $-80^{\circ} \mathrm{C}$ in the laboratory until further processing. Sampling of the third replicate of the February and April 2019 samples failed as revealed later on by our inability to extract RNA from these filters despite repeated attempts.

\section{Nucleic acid extraction, $Q P C R$ and CARD-FISH analyses}

DNA and RNA were extracted separately from respective $0.22-\mu \mathrm{m}$ filters after a modified protocol designed previously ${ }^{57}$ as detailed in Supplementary Text. Quantitative PCR assays of total bacterial and archaeal 16S rRNA genes as well as archaeal amoA were performed as described recently ${ }^{16}$. The amoA qPCR assay was specifically designed to target archaeal amoA retrieved from the water column of Lake Constance. Efficiency of qPCR assays targeting the archaeal amoA and the total bacterial and archaeal 16S rRNA genes were on average $72.5 \pm 4.0 \%$ and $91.3 \pm 1.6 \%$, respectively. After each run, qPCR specificity was checked with a melting curve. In addition, qPCR products from selected runs were visualized on a $2.5 \%$-agarose gel to verify absence of unspecific PCR products. PCR-inhibitory substances were not evident by qPCR analyses of dilution series of two selected lake water DNA extracts.

For CARD-FISH analysis, $50 \mathrm{ml}$ of lake water was fixed with paraformaldehyde (final concentration $1 \%$, without methanol, Electron Microscopy Sciences) overnight at $4^{\circ} \mathrm{C}$. Cells were filtered onto $0.2 \mu \mathrm{m}$ polycarbonate filters (GTTP, Merck Millipore) and washed with filter-sterilized lake water. Filters were stored at $-20^{\circ} \mathrm{C}$ until analysis. Before CARD-FISH, cells on filter sections were immobilized by embedding in $0.1 \%$ low-gelling agarose (MetaPhor ${ }^{\mathrm{TM}}$, Lonza, Rockland, ME, USA). CARD-FISH was performed using a HRP-labeled oligonucleotide probe specific for Nitrososphaeria (HRP-labeled Thaum726 [GCTTTCATCCCTCACCGTC] and unlabeled competitors [Thaum726_compA: GCTTTCGTCCCTCACCGTC, Thaum726_compB: GCTTTCATCCCTCACTGTC]) ${ }^{58,59}$. Negative controls using probe NonEUB [ACTCCTACGGGAGGCAGC] ${ }^{60}$ were performed according to a defined protocol ${ }^{61}$ to exclude unspecific signals. Further CARD-FISH analysis was done as described recently ${ }^{38}$ and in the Supplementary Text. 
Archaeal nitrification in lakes

\section{Next generation sequencing and bioinformatics processing}

Metagenome sequencing libraries were prepared with the NEBNext ${ }^{\circledast}$ Ultra ${ }^{\mathrm{TM}}$ DNA Library Prep Kit for Illumina ${ }^{\circledR}$ (New England Biolabs GmbH, Frankfurt am Main, Germany) and sequenced on an Illumina NextSeq500 sequencer using $2 \times 150 \mathrm{bp}$. This resulted in $0.6-2.7 \times 10^{8}$ reads per metagenome with an average of $1.3 \times 10^{8}$ reads $(8.8-41 \mathrm{Gbp}$, average $20 \mathrm{Gbp})$. Raw Illumina reads were quality checked with FastQC v.0.11.8 $8^{62}$ and subsequently quality filtered and trimmed using Sickle v1.33 $3^{63}$. Thereafter, reads were assembled with Megahit v1.1.2 ${ }^{64}$ and binned with maxbin2 v2.2.4 ${ }^{65}$. A coassembly of the Nov 2017, Dec 2017, and Feb 2018 metagenomes resulted in the best AOA bin. To refine this bin, DNA from November 2017 was sequenced in addition by PacBio sequencing on a Sequel instrument (Pacific Biosciences, Menlo Park, CA, USA) using circular consensus sequencing with a target length of $2 \mathrm{kbp}$. Raw PacBio reads were quality controlled with smrt analysis using an accuracy of 0.999; the number of resulting CCS bases was $0.55 \mathrm{Gbp}$. The original Illumina AOA bin was used as trusted contigs in spades v3.11.1 $1^{66}$ and re-assembled with Sequel-reads for gap closure. A subsequent binning in metabat2 $\mathrm{V} 2.12 .1^{67}$ resulted in the final MAG AOA-LC4. MAGs related to $\mathrm{AOB}, \mathrm{NOB}$ or comammox could not be further refined by long PacBio reads. All MAGs were tested for completeness, strain heterogeneity, and contamination using CheckM v1.0.7 $7^{27}$ and for their index of replication using iRep v1.1028. MAGs and single contigs were screened for the presence of the functional marker genes $a m o A$ and $n x r B$ by both blastp $v 2.10 .1^{68}$ (e-value threshold $1^{-10}$ ) and hmmsearch v3.3 ${ }^{69}$ (e-value threshold $1^{-5}$ ). The latter was based on $\mathrm{hmm}$-models retrieved from the fungene database with manual curation [amoA_AOA.hmm (Feifei Liu), amoA_AOB.hmm (RDP) amoA_comammox.hmm (Yang Ouyang), nxrB.hmm (RDP), fungene.cme.msu.edu] ${ }^{70}$. MAG AOA-LC4 was annotated using the Microscope platform ${ }^{71}$. The automated annotation was manually refined using annotation rules laid out before ${ }^{72}$. Additional MAGs were annotated with PROKKA $v 1.12^{73}$ and curated manually for their functional marker genes $\operatorname{amo} A B C, h a o$, and $n x \operatorname{xAB}$, where appropriate.

For metatranscriptome sequencing, messenger RNA (mRNA) was enriched from total RNA extracts by depleting ribosomal RNA with the Ribo-off rRNA Depletion Kit for bacteria (Vazyme, Nanjing, China). Thereafter, the sequencing library was prepared with the TruSeq ${ }^{\circledR}$ Stranded mRNA Library Prep (Illumina) and sequenced on a NextSeq500 sequencer using $2 \times 150 \mathrm{bp}$. The sequencing depth ranged between $0.7-1.9 \times 10^{8}$ reads per metatranscriptome with an average of $1.2 \times 10^{8}$ reads (10$27 \mathrm{Gbp}$, average $17 \mathrm{Gbp}$ ). Raw reads were quality filtered and trimmed using trimmomatic $0.38^{74}$ and the fastx toolkit v0.0.14 (hannonlab.cshl.edu/fastx_toolkit). Residual ribosomal reads were removed using SortMeRNA v2.1 $\mathrm{b}^{75}$. Curated metatranscriptome reads were mapped against MAGs and contigs of interest using bowtie $2 \mathrm{v} 2.30^{76}$ to determine the transcription levels of individual genes. Subsequent network analysis of co-transcribed genes of MAG AOA-LC4 was based on genes with transcription values higher than the median transcription of all AOA-LC4 genes (35.35 FPKM). 
Archaeal nitrification in lakes

Transcription values were correlated pairwise using Spearman correlation; only significant (FDRcorrected $p$-value $<0.05)$ correlations with a correlation coefficient of $r_{S}>0.8$ were further processed. For the final network construction, only genes, which correlated in their transcriptional response to at least two of the either $a m o A, a m o B$ or $a m o C$ were taken into account. The network was created with the R package igraph v1.2.5 ${ }^{77}$ and refined with cytoscape v3.8.1 ${ }^{78}$.

\section{Phylogenetic analyses}

Phylogenomic analyses of the nitrifying MAGs were performed on the basis of concatenated amino acid alignments of 122 translated archaeal or 120 bacterial single copy genes ${ }^{79,80}$. Alignments were generated using GTDB-Tk v0.3.2 ${ }^{81}$ and maximum likelihood trees were constructed using IQ-tree v1.6.12 ${ }^{82}$. Branch support was tested with the Shimodaira-Hasegawa approximate likelihood-ratio test $^{83}$ and ultrafast bootstrap ${ }^{82}$ options in IQ-tree. Genome-wide average nucleic and amino acid identities (ANI and AAI, respectively) were calculated with the online tool (enve-omics.ce.gatech.edu) developed previously ${ }^{84}$ using default settings. Maximum likelihood trees for AOB-amoA, comammoxamoA and NOB/comammox-nxrB genes were constructed in IQ-tree based on manually curated alignments established in ARB v6.0.3 $3^{85}$.

\section{Ammonia oxidation rate measurements}

To determine ammonia oxidation and ammonium assimilation rates, ${ }^{15} \mathrm{~N}_{-} \mathrm{NH}_{4}{ }^{+}$-tracer experiments were carried out as described recently ${ }^{38}$. In June, July, August and November 2019, water was sampled from $85 \mathrm{~m}$ depth using a Niskin bottle. Thereafter, 4.5 I were distributed on board to 5-I glass bottles leaving a headspace of $0.5 \mathrm{I}$. Bottles were sealed with oxalic acid and sodium hydroxide cleaned butyl rubber stoppers and wrapped in aluminum foil to protect them from light. Within 1-7 $\mathrm{h}$ after sampling, ${ }^{15} \mathrm{~N}$-tracer experiments were started by addition of $\left({ }^{15} \mathrm{NH}_{4}\right)_{2} \mathrm{SO}_{4}{ }^{2-}(10 \mu \mathrm{M}$ final ${ }^{15} \mathrm{~N}$-concentration) and bottles were incubated at in-situ temperature $\left(4^{\circ} \mathrm{C}\right)$ in the dark. All incubations were done in biological triplicates. Subsamples of $10 \mathrm{ml}$ were taken for nitrification rate measurements over a time period of $48 \mathrm{~h}$ (67 h in June), filter-sterilized $(0.2 \mu \mathrm{m})$ and filters were frozen at $-20^{\circ} \mathrm{C}$. ${ }^{15} \mathrm{~N}$-ammonium labeling percentage was inferred in two steps: First, in situ ammonium concentrations were determined using the spectrophotometric salicylate method ${ }^{86}$. Second, in situ concentrations were put into relation to added ${ }^{15} \mathrm{~N}$-ammonium in samples taken immediately after isotope addition, which was measured by conversion to $\mathrm{N}_{2}$ using alkaline hypobromite as described before ${ }^{87} .{ }^{15} \mathrm{~N}$-ammonium labeling percentage was $>99 \%$ in all samples. Thereafter, ammonia oxidation rates were determined from combined ${ }^{15} \mathrm{~N}$-nitrite and ${ }^{15} \mathrm{~N}$-nitrate increase over time. First, ${ }^{15} \mathrm{~N}$-nitrite was measured by conversion to $\mathrm{N}_{2}$ with sulfamic acid ${ }^{88}$ and ${ }^{29} \mathrm{~N}_{2}$ was measured by gas chromatography isotope ratio mass spectrometry on a customized TraceGas coupled to a multicollector IsoPrime100 (Isoprime, Manchester, UK). After the ${ }^{15} \mathrm{~N}-\mathrm{NO}_{2}$ 


\section{Archaeal nitrification in lakes}

404

405

406

407

408

409

410

411

412

413

414

415

416

417

418

419

420

421

422

423

424

425

426

427

428

429

430

431

432

433

434

435

measurement, nitrate was reduced to nitrite using spongy cadmium and subsequently converted to $\mathrm{N}_{2}$ via sulfamic acid ${ }^{88,89}$. For ammonia oxidation rate calculation, ${ }^{15} \mathrm{~N}$-nitrite and ${ }^{15} \mathrm{~N}$-nitrate were set to zero at the first sampling time point after tracer addition, and ${ }^{15} \mathrm{~N}$-nitrite and ${ }^{15} \mathrm{~N}$-nitrate per time point were summed up to give the total ${ }^{15} \mathrm{NOx}$ production. Rates were inferred from the slopes of linear regressions; only slopes that were significantly different from zero are reported $(P<0.05$, onesided t-distribution test).

\section{Single cell ${ }^{15} \mathrm{~N}$-uptake measurements from combined CARD-FISH nanoSIMS}

After $48 \mathrm{~h}$ of the ${ }^{15} \mathrm{~N}-\mathrm{NH}_{4}^{+}$-tracer incubation experiment in November 2019, water samples were taken for Nitrososphaeria-specific CARD-FISH and subsequent nanoSIMS analyses. A subsample of incubated water $(50 \mathrm{ml}$ ) was fixed and used for CARD-FISH as described above, but without embedding filter sections in agarose. After CARD-FISH and DAPI staining, regions of interest (ROIs) were marked on a laser microdissection microscope (6000 B, Leica) and images of CARD-FISH signals were acquired on an epifluorescence microscope (Axio Imager, Zeiss). After image acquisition, the filters were sputtered with a $7 \mathrm{~nm}$ gold layer to create a conductive surface for nanoSIMS analyses. Single-cell ${ }^{15} \mathrm{~N}$-uptake from ${ }^{15} \mathrm{~N}$-ammonium was determined using a nanoSIMS 50L (CAMECA), as previously described ${ }^{90}$. Instrument performance was monitored regularly on graphite planchet and on caffeine standards. Due to the small size of AOA $(<1 \mu \mathrm{m})$, samples were only briefly $(10-20 \mathrm{~s})$ pre-sputtered with a $\mathrm{Cs}+$ beam $(\sim 300 \mathrm{pA})$ before measurement. Measurements were performed on a field size of $10 \times 10 \mu \mathrm{m}$ to $15 \times 15 \mu \mathrm{m}$ with a dwelling time of $2 \mathrm{~ms}$ per pixel and $256 \times 256$ pixel resolution over 25-40 planes. Analysis of the acquired data was performed using the Look@NanoSIMS software package ${ }^{91}$. Single cell growth and $\mathrm{N}$-assimilation rates were calculated as described recently ${ }^{44}$. We did not account for a possible ${ }^{15} \mathrm{~N}$-isotope dilution effect introduced by CARD-FISH $^{92-94}$, as the strength of the effect is dependent on cell growth phase, activity and type, which varies strongly in environmental samples. Therefore, the reported single cell growth and ammonium assimilation rates are a conservative estimate.

\section{AOA carbon content calculations}

The carbon content of individual AOA cells was inferred according to the nonlinear relationship between carbon mass and cell volume (Eq. 1 ) as recently established by Khachikyan et al. ${ }^{41}$ :

Eq. 1

$$
m_{\text {carbon }}=197 \times V^{0.46},
$$

with $m_{\text {carbon }}$ being the mass of carbon in femtograms and $V$ being the volume in cubic micrometers of an average AOA cell. $V$ was calculated assuming a prolate spheroid cell shape according to Eq. 2 as laid out before ${ }^{95}$ : 
437 with $W$ being the width of the cell and $L$ being the length as inferred from the nanoSIMS 438 measurements. Thereafter, the volumetric carbon content of the AOA population was calculated for 439 each time point of our archaeal amoA qPCR survey (Fig. 1d) by multiplying the carbon content of a single AOA cell $\left(m_{\text {carbon }}\right)$ with the total abundance of AOA $\left(A_{q P C R}\right)$ as inferred by archaeal amoA qPCR:

This volumetric $\mathrm{C}$ content was integrated over the water column of the hypolimnion and compared to the depth-integrated C content of the phytoplankton, which was inferred from depth-resolved Chlorophyll $a$ concentrations using the $\mathrm{C}: \mathrm{Chl} a$ (weight:weight) conversion factor of $31.5^{96}$.

\section{AOA nitrogen flux calculations}

Cell-specific nitrification rates of the AOA-LC4 population ( $\left.R_{\text {cell-specific }}\right)$ were inferred by dividing measured bulk nitrification rates $\left(R_{\text {bulk }}\right)$ by the total abundance of AOA as inferred by archaeal amoA qPCR $\left(A_{q P C R}\right)$ obtained at the same time points:

Eq. 4

$$
R_{\text {cell-specific }}=\frac{R_{\text {bulk }}}{A_{q P C R}}
$$

The average of cell-specific nitrification rates was used to infer the annual volumetric nitrification rate of the AOA-LC4 population ( $R_{\text {annual }}$ ) by integrating over our complete data set of total AOA abundances in the years 2017 to 2019:

Eq. 5

$$
R_{\text {annual }}=\frac{\sum_{1}^{n}\left[\left(\bar{R}_{\text {cell-specific }} \frac{A_{q P C R, n}+A_{q P C R, n-1}}{2}\right)\left(t_{n}-t_{n-1}\right)\right]}{\text { years }}
$$

Whenever average values were used to calculate the mean, e.g., to estimate average nitrification rates over the year, the propagation of uncertainty was calculated and the resulting uncertainty provided next to the mean.

\section{Data Availability} under bioproject number PRJNA691101. 
Archaeal nitrification in lakes

461

462

463

464

465

466

467

468

469

470

471

472

473

474

475

476

477

478

479

480

481

482

483

484

485

486

487

488

489

490

491

492

493

494

495

496

497

498

499

500

501

\section{References}

1. Jetten, M. S. M. The microbial nitrogen cycle. Environ. Microbiol. 10, 2903-2909 (2008).

2. Alves, R. J. E., Minh, B. Q., Urich, T., Von Haeseler, A. \& Schleper, C. Unifying the global phylogeny and environmental distribution of ammonia-oxidising archaea based on amoA genes. Nat. Commun. 9, 1-17 (2018).

3. Könneke, M. et al. Isolation of an autotrophic ammonia-oxidizing marine archaeon. Nature 437, 543-546 (2005).

4. Bock, E. \& Wagner, M. Oxidation of Inorganic Nitrogen Compounds as an Energy Source. in The Prokaryotes 2, 457-495 (2006).

5. Daims, H., Lücker, S. \& Wagner, M. A New Perspective on Microbes Formerly Known as Nitrite-Oxidizing Bacteria. Trends Microbiol. 24, 699-712 (2016).

6. Daims, H. et al. Complete nitrification by Nitrospira bacteria. Nature 528, 504-509 (2015).

7. Van Kessel, M. A. H. J. et al. Complete nitrification by a single microorganism. Nature 528, 555-559 (2015).

8. Hou, J., Song, C., Cao, X. \& Zhou, Y. Shifts between ammonia-oxidizing bacteria and archaea in relation to nitrification potential across trophic gradients in two large Chinese lakes (Lake Taihu and Lake Chaohu). Water Res. 47, 2285-2296 (2013).

9. Hugoni, M. et al. Dynamics of ammonia-oxidizing Archaea and Bacteria in contrasted freshwater ecosystems. Res. Microbiol. 164, 360-370 (2013).

10. Mukherjee, M., Ray, A., Post, A. F., McKay, R. M. \& Bullerjahn, G. S. Identification, enumeration and diversity of nitrifying planktonic archaea and bacteria in trophic end members of the Laurentian Great Lakes. J. Great Lakes Res. 42, 39-49 (2016).

11. Okazaki, Y. \& Nakano, S. I. Vertical partitioning of freshwater bacterioplankton community in a deep mesotrophic lake with a fully oxygenated hypolimnion (Lake Biwa, Japan). Environ. Microbiol. Rep. 8, 780-788 (2016).

12. Vissers, E. W. et al. Temporal and spatial coexistence of archaeal and bacterial amoA genes and gene transcripts in Lake Lucerne. Archaea 2013, 289478 (2013).

13. Yang, Y. et al. Ammonia-oxidizing archaea and bacteria in water columns and sediments of a highly eutrophic plateau freshwater lake. Environ. Sci. Pollut. Res. 23, 15358-15369 (2016).

14. Gwak, J. H. et al. Archaeal nitrification is constrained by copper complexation with organic matter in municipal wastewater treatment plants. ISME J. 14, 335-346 (2020).

15. Alfreider, A. et al. Autotrophic carbon fixation strategies used by nitrifying prokaryotes in freshwater lakes. FEMS Microbiol. Ecol. 94, 1-12 (2018).

16. Herber, J. et al. A single Thaumarchaeon drives nitrification in deep oligotrophic Lake Constance. Environ. Microbiol. 22, 212-228 (2020).

17. Callieri, C., Hernández-Avilés, S., Salcher, M. M., Fontaneto, D. \& Bertoni, R. Distribution patterns and environmental correlates of Thaumarchaeota abundance in six deep subalpine lakes. Aquat. Sci. 78, 215-225 (2016).

18. Pollet, T., Berdjeb, L., Chardon, C. \& Jacquet, S. Contrasting temporal patterns in ammoniaoxidizing archaeal community dynamics in two peri-alpine lakes with different trophic status. Aquat. Microb. Ecol. 81, 95-108 (2018). 
19. Small, G. E. et al. Rates and controls of nitrification in a large oligotrophic lake. Limnol. Oceanogr. 58, 276-286 (2013).

20. Urbach, E. et al. Unusual bacterioplankton community structure in ultra-oligotrophic Crater Lake. Limnol. Oceanogr. 46, 557-572 (2001).

21. Karner, M. B., DeLong, E. F. \& Karl, D. M. Archaeal dominance in the mesopelagic zone of the Pacific Ocean. Nature 409, 507-510 (2001).

22. Lehtovirta-Morley, L. E. Ammonia oxidation: Ecology, physiology, biochemistry and why they must all come together. FEMS Microbiol. Lett. 365, 1-9 (2018).

23. Petri, M. Water Quality of Lake Constance. in The Rhine 127-138 (Springer Berlin Heidelberg, 2006).

24. Güde, H. \& Straile, D. Bodensee Ökologie Und Anthropogene Belastungen Eines Tiefen Voralpensees. (Schweizerbart Science Publishers, 2016).

25. Rinke, C. et al. A standardized archaeal taxonomy for the Genome Taxonomy Database. Nat. Microbiol. 6, 946-959 (2021).

26. Herbold, C. W. et al. Ammonia-oxidising archaea living at low pH: Insights from comparative genomics. Environ. Microbiol. 19, 4939-4952 (2017).

27. Parks, D. H., Imelfort, M., Skennerton, C. T., Hugenholtz, P. \& Tyson, G. W. CheckM: assessing the quality of microbial genomes recovered from isolates, single cells, and metagenomes. Genome Res. 25, 1043-1055 (2015).

28. Brown, C. T., Olm, M. R., Thomas, B. C. \& Banfield, J. F. Measurement of bacterial replication rates in microbial communities. Nat. Biotechnol. 34, 1256-1263 (2016).

29. Long, A. M., Hou, S., Ignacio-Espinoza, J. C. \& Fuhrman, J. A. Benchmarking microbial growth rate predictions from metagenomes. ISME J. 15, 183-195 (2021).

30. Emiola, A. \& Oh, J. High throughput in situ metagenomic measurement of bacterial replication at ultra-low sequencing coverage. Nat. Commun. 9, 4956 (2018).

31. Gao, Y. \& Li, H. Quantifying and comparing bacterial growth dynamics in multiple metagenomic samples. Nat. Methods 15, 1041-1044 (2018).

32. Könneke, M. et al. Ammonia-oxidizing archaea use the most energy-efficient aerobic pathway for CO2 fixation. Proc. Natl. Acad. Sci. U. S. A. 111, 8239-8244 (2014).

33. Walker, C. B. et al. Nitrosopumilus maritimus genome reveals unique mechanisms for nitrification and autotrophy in globally distributed marine crenarchaea. Proc. Natl. Acad. Sci. 107, 8818-8823 (2010).

34. Carini, P., Dupont, C. L. \& Santoro, A. E. Patterns of thaumarchaeal gene expression in culture and diverse marine environments. Environ. Microbiol. 20, 2112-2124 (2018).

35. Kozlowski, J. A., Stieglmeier, M., Schleper, C., Klotz, M. G. \& Stein, L. Y. Pathways and key intermediates required for obligate aerobic ammonia-dependent chemolithotrophy in bacteria and Thaumarchaeota. ISME J. 10, 1836-1845 (2016).

36. Pester, M. et al. NxrB encoding the beta subunit of nitrite oxidoreductase as functional and phylogenetic marker for nitrite-oxidizing Nitrospira. Environ. Microbiol. 16, 3055-3071 (2014).

37. Stein, L. Y. Insights into the physiology of ammonia-oxidizing microorganisms. Curr. Opin. Chem. Biol. 49, 9-15 (2019). 
38. Kitzinger, K. et al. Cyanate and urea are substrates for nitrification by Thaumarchaeota in the marine environment. Nat. Microbiol. 4, 234-243 (2019).

39. Alonso-Sáez, L. et al. Role for urea in nitrification by polar marine Archaea. Proc. Natl. Acad. Sci. U. S. A. 109, 17989-17994 (2012).

40. Herndl, G. J. et al. Contribution of Archaea to Total Prokaryotic Production in the Deep Atlantic Ocean. Appl. Environ. Microbiol. 71, 2303 LP - 2309 (2005).

41. Khachikyan, A. et al. Direct Cell Mass Measurements Expand the Role of Small Microorganisms in Nature. Appl. Environ. Microbiol. 85, 1-12 (2019).

42. Sterner, R. C:N:P stoichiometry in Lake Superior: freshwater sea as end member. Inl. Waters 1, 29-46 (2011).

43. Wuchter, C. et al. Archaeal nitrification in the ocean. Proc. Natl. Acad. Sci. U. S. A. 103, 1231712322 (2006).

44. Kitzinger, K. et al. Single cell analyses reveal contrasting life strategies of the two main nitrifiers in the ocean. Nat. Commun. 11, (2020).

45. Adam, G., Läuger, P. \& Stark, G. Physikalische Chemie Und Biophysik. (Springer, 2009).

46. Häse, C., Gaedke, U., Seifried, A., Beese, B. \& Tilzer, M. M. Phytoplankton response to reoligotrophication in large and deep Lake Constance: Photosynthetic rates and chlorophyll concentrations. Arch. für Hydrobiol. 53, 159-178 (1998).

47. Mukherjee, M., Ray, A., Post, A. F., McKay, R. M. \& Bullerjahn, G. S. Identification, enumeration and diversity of nitrifying planktonic archaea and bacteria in trophic end members of the Laurentian Great Lakes. J. Great Lakes Res. 42, 39-49 (2016).

48. Brochier-Armanet, C. et al. A standardized bacterial taxonomy based on genome phylogeny substantially revises the tree of life. ISME J. 9, 1-15 (2018).

49. Williamson, C. E., Saros, J. E., Vincent, W. F. \& Smol, J. P. Lakes and reservoirs as sentinels,

50. Fink, G. et al. KlimBo - Klimawandel am Bodensee. IGKB - Blaue R. 60, (2015).

51. Auguet, J. C., Triadó-Margarit, X., Nomokonova, N., Camarero, L. \& Casamayor, E. O. Vertical

52. Coci, M., Odermatt, N., Salcher, M. M., Pernthaler, J. \& Corno, G. Ecology and Distribution of segregation and phylogenetic characterization of ammonia-oxidizing Archaea in a deep oligotrophic lake. ISME J. 6, 1786-1797 (2012).

\section{Vissers, E. W. et al. Seasonal and vertical distribution of putative ammonia-oxidizing} thaumarchaeotal communities in an oligotrophic lake. FEMS Microbiol. Ecol. 83, 515-526 (2013).

54. Restrepo-Ortiz, C. X., Auguet, J.-C. \& Casamayor, E. O. Targeting spatiotemporal dynamics of planktonic SAGMGC-1 and segregation of ammonia-oxidizing thaumarchaeota ecotypes by newly designed primers and quantitative polymerase chain reaction. Environ. Microbiol. 16, 689-700 (2014).

55. Holmes, R. M., Aminot, A., Kérouel, R., Hooker, B. A. \& Peterson, B. J. A simple and precise method for measuring ammonium in marine and freshwater ecosystems. Can. J. Fish. Aquat. Sci. 56, 1801-1808 (1999).

\section{Tilzer, M. M. The importance of fractional light absorption by photosynthetic pigments for}


phytoplankton productivity in Lake Constance. Limnol. Oceanogr. 28, 833-846 (1983).

57. Schneider, D., Wemheuer, F., Pfeiffer, B. \& Wemheuer, B. Extraction of Total DNA and RNA from Marine Filter Samples and Generation of a cDNA as Universal Template for Marker Gene Studies. Methods Mol. Biol. 1539, 13-22 (2017).

58. Beam, J. P. Geobiological interactions of archaeal populations in acidic and alkaline geothermal springs of Yellowstone National Park, WY, USA. (Montana State University, 2015).

59. Sauder, L. A. et al. Cultivation and characterization of Candidatus Nitrosocosmicus exaquare, an ammonia-oxidizing archaeon from a municipal wastewater treatment system. ISME J. 11, 1142-1157 (2017).

60. Wallner, G., Amann, R. \& Beisker, W. Optimizing fluorescent in situ hybridization with rRNAtargeted oligonucleotide probes for flow cytometric identification of microorganisms. Cytometry 14, 136-143 (1993).

61. Pernthaler, A., Pernthaler, J. \& Amann, R. Sensitive multi-color fluorescence in situ hybridization for the identification of environmental microorganisms. in Molecular Microbial Ecology Manual (eds. Kowalchuk, G., de Bruijn, F. J., Head, I. M., Akkermans, A. D. L. \& van Elsas, J. D.) 711-726 (Kluwer Academic Publishers, 2004).

62. Andrews, S. FASTQC: A quality control tool for high throughput sequence data. https://www.bioinformatics.babraham.ac.uk/projects/fastqc/. [Software]. (2010).

63. Joshi, N. \& Fass, J. Sickle: A sliding-window, adaptive, quality-based trimming tool for FastQ files (Version 1.33) [Software]. (2011).

64. Li, D., Liu, C. M., Luo, R., Sadakane, K. \& Lam, T. W. MEGAHIT: An ultra-fast single-node solution for large and complex metagenomics assembly via succinct de Bruijn graph. Bioinformatics 31, 1674-1676 (2015).

65. Wu, Y. W., Simmons, B. A. \& Singer, S. W. MaxBin 2.0: An automated binning algorithm to recover genomes from multiple metagenomic datasets. Bioinformatics 32, 605-607 (2016).

66. Nurk, S., Meleshko, D., Korobeynikov, A. \& Pevzner, P. A. metaSPAdes: a new versatile metagenomic assembler. Genome Res. 27, 824-834 (2017).

67. Kang, D. D. et al. MetaBAT 2: an adaptive binning algorithm for robust and efficient genome reconstruction from metagenome assemblies. PeerJ 7, e7359 (2019).

68. Altschul, S. F., Gish, W., Miller, W., Myers, E. W. \& Lipman, D. J. Basic local alignment search tool. J. Mol. Biol. 215, 403-410 (1990).

69. Eddy, S. R. A new generation of homology search tools based on probabilistic inference. Genome Inform. 23, 205-211 (2009).

70. Fish, J. A. et al. FunGene: the functional gene pipeline and repository. Front. Microbiol. 4, 291 (2013).

71. Vallenet, D. et al. MicroScope in 2017: an expanding and evolving integrated resource for community expertise of microbial genomes. Nucleic Acids Res. 45, D517-D528 (2016).

72. Hausmann, B., Pelikan, C., Rattei, T., Loy, A. \& Pester, M. Long-Term Transcriptional Activity at Zero Growth of a Cosmopolitan Rare Biosphere Member. MBio 10, e02189-18 (2019).

73. Seemann, T. Prokka: rapid prokaryotic genome annotation. Bioinformatics 30, 2068-2069 (2014).

74. Bolger, A. M., Lohse, M. \& Usadel, B. Trimmomatic: a flexible trimmer for Illumina sequence 
Archaeal nitrification in lakes

data. Bioinformatics 30, 2114-2120 (2014).

75. Kopylova, E., Noé, L. \& Touzet, H. SortMeRNA: fast and accurate filtering of ribosomal RNAs in metatranscriptomic data. Bioinformatics 28, 3211-3217 (2012).

76. Langmead, B. \& Salzberg, S. L. Fast gapped-read alignment with Bowtie 2. Nat. Methods 9, 357-359 (2012).

77. Csardi, G. \& Nepusz, T. The igraph software package for complex network research. InterJournal, Complex Syst. 1695, 1-9 (2006).

78. Smoot, M. E., Ono, K., Ruscheinski, J., Wang, P.-L. \& Ideker, T. Cytoscape 2.8: new features for data integration and network visualization. Bioinformatics 27, 431-432 (2011).

79. Parks, D. H. et al. A standardized bacterial taxonomy based on genome phylogeny substantially revises the tree of life. Nat. Biotechnol. 36, 996 (2018).

80. Parks, D. H. et al. A complete domain-to-species taxonomy for Bacteria and Archaea. Nat. Biotechnol. 38, 1079-1086 (2020).

81. Chaumeil, P.-A., Mussig, A. J., Hugenholtz, P. \& Parks, D. H. GTDB-Tk: a toolkit to classify genomes with the Genome Taxonomy Database. Bioinformatics 36, 1925-1927 (2019).

82. Nguyen, L.-T., Schmidt, H. A., von Haeseler, A. \& Minh, B. Q. IQ-TREE: A Fast and Effective Stochastic Algorithm for Estimating Maximum-Likelihood Phylogenies. Mol. Biol. Evol. 32, 268-274 (2014).

83. Guindon, S. et al. New algorithms and methods to estimate maximum-likelihood phylogenies: assessing the performance of PhyML 3.0. Syst. Biol. 59, 307-321 (2010).

84. Rodriguez-R, L. M. \& Konstantinidis, K. Bypassing Cultivation To Identify Bacterial Species: Culture-independent genomic approaches identify credibly distinct clusters, avoid cultivation bias, and provide true insights into microbial species. Microbe Mag. 9, 111-118 (2014).

85. Ludwig, W. et al. ARB: a software environment for sequence data. Nucleic Acids Res. 32, 1363-1371 (2004).

86. Kempers, A. J. \& Kok, C. J. Re-examination of the determination of ammonium as the indophenol blue complex using salicylate. Anal. Chim. Acta (1989).

87. Warembourg, F. R. Nitrogen Fixation in Soil and Plant Systems. in Nitrogen Isotope Techniques 157-180 (Academic: New York, 1993).

88. Füssel, J. et al. Nitrite oxidation in the Namibian oxygen minimum zone. ISME J. 6, 1200-1209 (2012).

89. Mcllvin, M. R. \& Altabet, M. A. Chemical conversion of nitrate and nitrite to nitrous oxide for nitrogen and oxygen isotopic analysis in freshwater and seawater. Anal. Chem. 77, 5589-5595 (2005).

90. Martínez-Pérez, C. et al. The small unicellular diazotrophic symbiont, UCYN-A, is a key player in the marine nitrogen cycle. Nat. Microbiol. 1, 1-13 (2016).

91. Polerecky, L. et al. Look@NanoSIMS - a tool for the analysis of nanoSIMS data in environmental microbiology. Environ. Microbiol. 14, 1009-1023 (2012).

92. Musat, N., Foster, R., Vagner, T., Adam, B. \& Kuypers, M. M. M. Detecting metabolic activities in single cells, with emphasis on nanoSIMS. FEMS Microbiol. Rev. 36, 486-511 (2012).

93. Woebken, D. et al. Revisiting N2 fixation in Guerrero Negro intertidal microbial mats with a 
bioRxiv preprint doi: https://doi.org/10.1101/2021.07.22.453385; this version posted July $22,2021$. The copyright holder for this preprint (which was not certified by peer review) is the author/funder. All rights reserved. No reuse allowed without permission.

Archaeal nitrification in lakes

668

669

670

671

672

673

674

675

676

677

678

679

680

681

682

683

684

685

686

687

688

689

690

691

692

693

694

695

functional single-cell approach. ISME J. 9, 485-496 (2015).

94. Meyer, N. R., Fortney, J. L. \& Dekas, A. E. NanoSIMS sample preparation decreases isotope enrichment: magnitude, variability and implications for single-cell rates of microbial activity. Environ. Microbiol. 23, 81-98 (2021).

95. Sun, J. \& Liu, D. Geometric models for calculating cell biovolume and surface area for phytoplankton. J. Plankton Res. 25, 1331-1346 (2003).

96. Jakobsen, H. H. \& Markager, S. Carbon-to-chlorophyll ratio for phytoplankton in temperate coastal waters: Seasonal patterns and relationship to nutrients. Limnol. Oceanogr. 61, 18531868 (2016).

\section{Acknowledgements}

We thank Alfred Sulger as captain of the RV Robert Lauterborn, Joseph Halder, Sylke Wiechmann, Julia Schmidt, Christian Fiek, Isabell Winter, Gabriele Glockgether, Nadine Rujanski, Fenna Alfke, Tine Jordan and Pia Mahler for technical support. We thank Dietmar Straile for provision of chlorophyll $a$ data and scientific exchange, Holger Daims for fruitful discussions as well as David Schleheck for providing laboratory space. This research was funded by the German Research Foundation (DFG, GRK 2272/1, project C2 to M.P. and B.S.), the University of Konstanz, the Leibniz Institute DSMZ and the Max Planck Society.

\section{Author contributions}

F.K., K.K., B.S., M.M.M.K. and M.P. designed the study; P.B. performed sequencing and sequencing library preparations and measured total ammonium; K.K. and S.L. ran nanoSIMS analyses; F.K., K.K., D.K.N. and M.P. analyzed samples and data. The manuscript was written by F.K. and M.P. with contributions from all co-authors.

\section{Competing interests}

The authors declare that they have no conflict of interest.

\section{Additional information}

Supplementary information is available for this paper. 
Archaeal nitrification in lakes

\section{Tables}

697 Table 1. Bulk nitrification rates $(n=3)$ and derived cell-specific AOA-driven nitrification rates in the 698 hypolimnion of Lake Constance. Cell-specific nitrification rates were inferred from nitrification rates 699 divided by the respective absolute abundance of AOA measured by archaeal amoA qPCR.

\begin{tabular}{|c|c|c|c|}
\hline $\begin{array}{l}\text { Sampling date } \\
\text { (yyyy-mm-dd) }\end{array}$ & $\begin{array}{c}\text { Nitrification rate in the } \\
\text { hypolimnion }\left(\mathrm{nmol} \mathrm{I} \mathrm{I}^{-1} \mathrm{~d}^{-1}\right)\end{array}$ & $\begin{array}{c}\text { amoA copy numbers } \\
\left(10^{4} \text { copies } \mathrm{ml}^{-1}\right)\end{array}$ & $\begin{array}{l}\text { Cell-specific nitrification rate } \\
\left(\mathrm{fmol} \text { cell }{ }^{-1} \mathrm{~d}^{-1}\right)\end{array}$ \\
\hline 2019-06-18 & $5.89 \pm 0.15$ & $2.50 \pm 0.63$ & $0.24 \pm 0.06$ \\
\hline 2019-07-29 & $4.61 \pm 0.41$ & n.d. & - \\
\hline $2019-08-28$ & $6.06 \pm 0.26$ & n.d. & - \\
\hline 2019-11-05 & $7.72 \pm 0.44$ & $3.81 \pm 1.55$ & $0.20 \pm 0.08$ \\
\hline
\end{tabular}




\section{Archaeal nitrification in lakes}
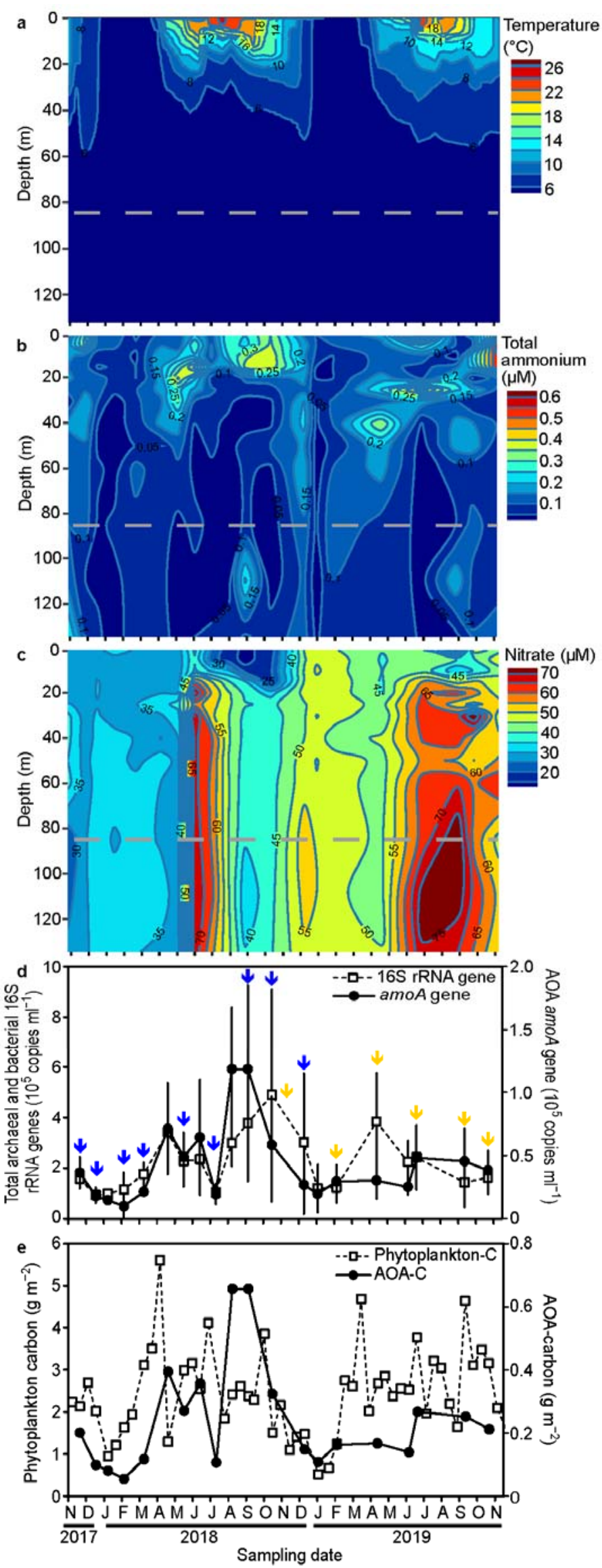

Figure 1. Seasonality of physicochemical parameters $(a-c)$, the total archaeal and bacterial picoplankton as well as the AOA population at $85 \mathrm{~m}$ depth (d), and the carbon budget of the phytoplankton and AOA population (e) over two consecutive years in the water column of Lake Constance. The sampling depth for $\mathrm{qPCR}$, metagenome and metatranscriptome analyses is indicated as a dashed grey line at $85 \mathrm{~m}$. Arrows indicate time points for metagenome (blue) and metatranscriptome (yellow) sampling. qPCR analyses were done in replicates of 3 or 4 , except for December $18^{\text {th }}, 2018$, where only duplicates could be measured for the AOA amoA. 


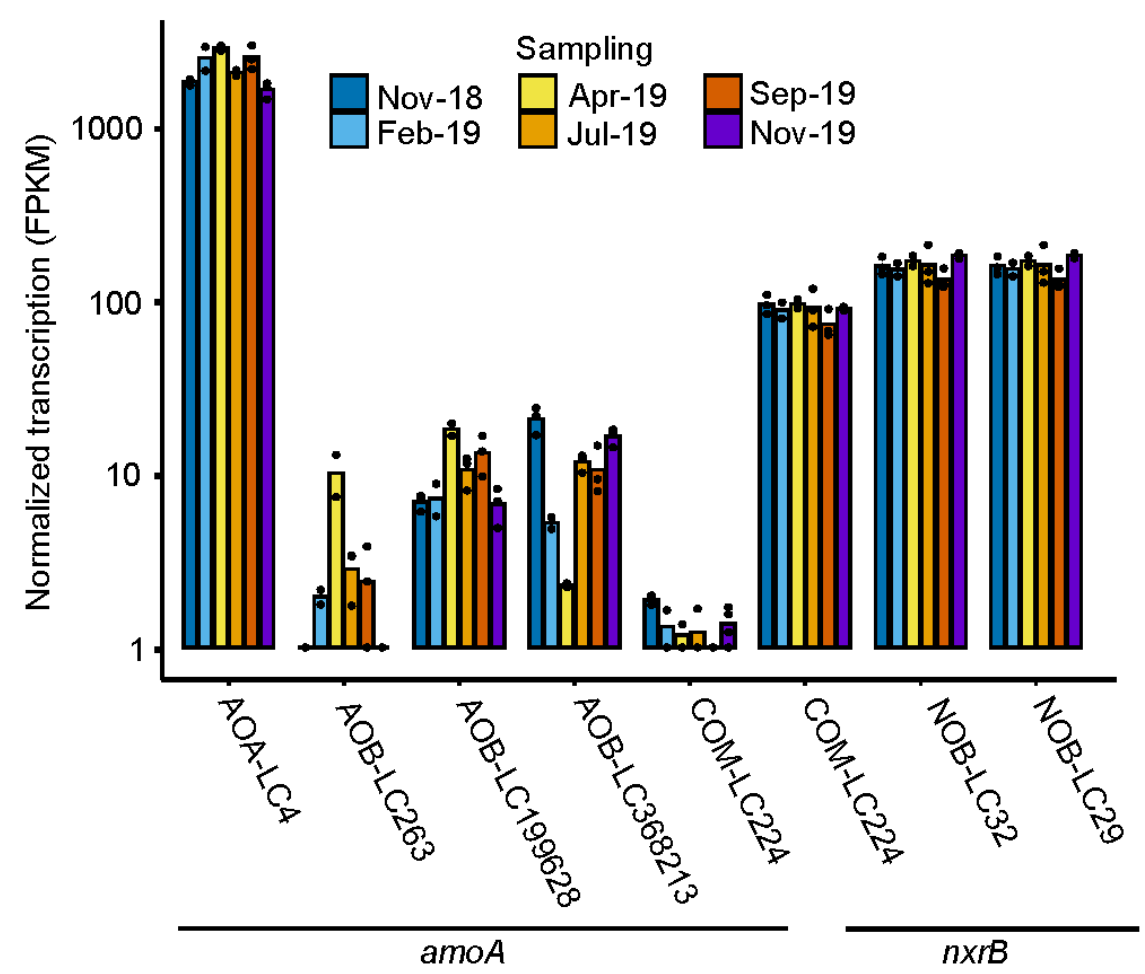

704 Figure 2. Year-round transcriptional activity of the nitrifying community in the hypolimnion (85 $\mathrm{m}$ depth) of Lake Constance based on metatranscriptomics. Transcription of amoA (encoding ammonia monooxygenase subunit A) as functional marker for all ammonia oxidizers, $n x r B$ (encoding nitrite oxidoreductase subunit B) as functional marker for all nitrite oxidizers, or both genes in the same MAG as indicator for comammox bacteria is shown across all identified nitrifying microorganisms. Bars represent the mean of three replicates, except for the February and April samples, where only two replicates could by analyzed. Individual replicates are indicated by single dots. FPKM values below 1 were set to 1 for a better representation on a $\log _{10}$-scale. FPKM, fragments per kilobase of transcripts per million mapped reads. 


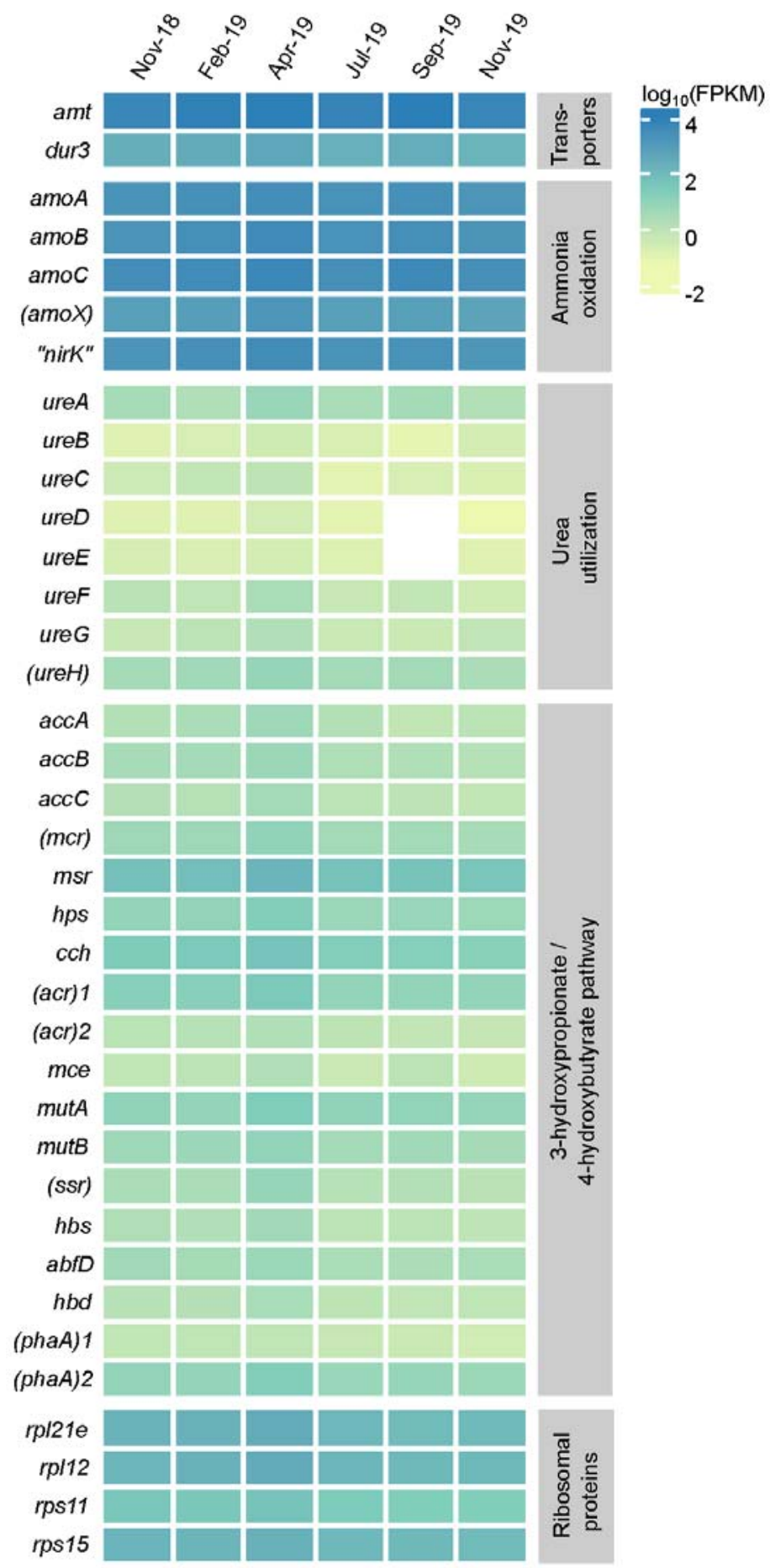

715 Figure 3: Seasonally-resolved transcription of genes involved in the nitrogen and carbon metabolism 716 of AOA-LC4 at $85 \mathrm{~m}$ depth. As reference housekeeping genes, the two highest transcribed genes 717 encoding either proteins of the large $(r p / 12, r p / 21 e)$ or small ribosomal subunit $(r p s 11, r p s 15)$ are shown at the bottom. Transcription values are represented as $\log _{10}$-transformed mean FPKM (fragments per kilobase of transcripts per million mapped reads) values for every time point. Values represent the mean of three replicates, except for the February and April samples, where only two replicates could by analyzed. No transcription of a specific gene is indicated in white. Putatively annotated genes are given in brackets; gene duplicates were consecutively numbered. 
Archaeal nitrification in lakes
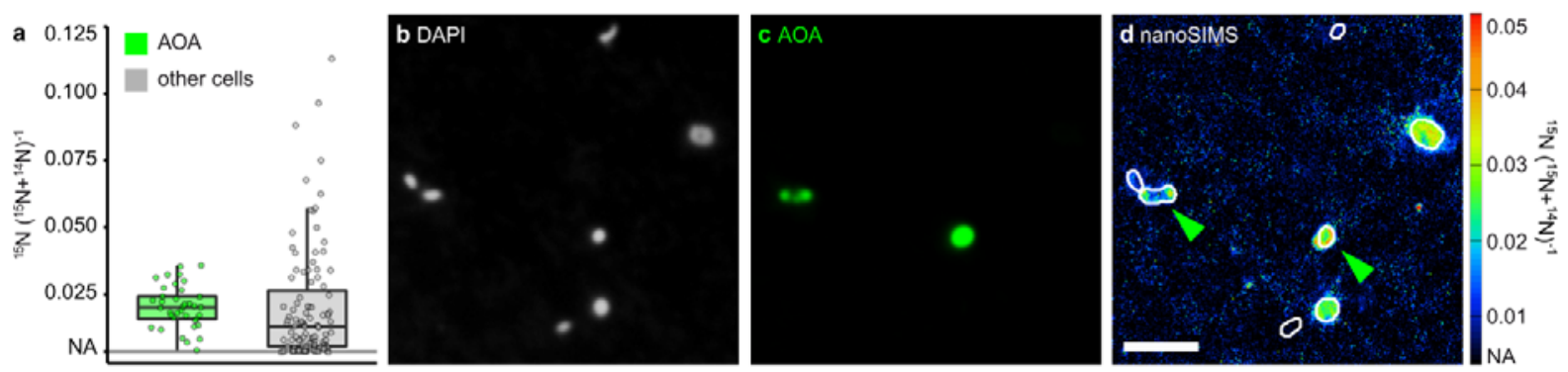

724 Figure 4: Single-cell ammonium uptake by AOA and non-target picoplankton cells in hypolimnetic water from $85 \mathrm{~m}$ depth determined by nanoSIMS combined with CARD-FISH analysis. (a) ${ }^{15} \mathrm{~N}$ enrichment of AOA $(n=37)$ and non-target cells $(n=105)$ after addition of ${ }^{15} \mathrm{~N}$-ammonium.

727 Representative images of (b) DAPI-stained cells, (c) corresponding CARD-FISH signals with a

728 Nitrososphaeria-specific probe, and (d) the corresponding ${ }^{15} \mathrm{~N}$-enrichment determined by nanoSIMS;

729 green arrows indicate AOA; scale bar $=2 \mu \mathrm{m}$. 